\title{
Occupational asthma in salbutamol process workers
}

\author{
R M Agius, A G Davison, E R Hawkins, A J Newman Taylor
}

\begin{abstract}
Occupational asthma after exposure to salbutamol in the pharmaceutical industry has not been previously reported. The occurrence of occupational asthma is described in two pharmaceutical process workers who were likely to have inhaled doses appreciably in excess of the therapeutic dose range. The findings do not lead to an unequivocal conclusion on the mechanism of the asthma but it was probably a pharmacological consequence of high exposure.
\end{abstract}

(Occup Environ Med 1994;51:397-399)

Occupational asthma has been described after the inhalation of a number of drugs or their precursors including glycyl compound, an intermediate in the production of salbutamol, ${ }^{1}$ but not to salbutamol itself. We report two pharmaceutical production workers with occupational asthma caused by inhaled salbutamol and describe the circumstances of their exposure. Salbutamol has been used extensively worldwide in the treatment of bronchial asthma because of its effective bronchodilator properties. Salbutamol base is used in metered dose aerosols whereas salbutamol sulphate is used in other preparations. ${ }^{2}$

\section{Description of process and exposure}

The process commenced with pure salbutamol base delivered to the site as a raw material and therefore did not include the primary synthesis previously described. ${ }^{1}$ Part of the salbutamol base was repackaged for distribution by scooping from large drums into smaller bags in a corner of an area measuring about $150 \mathrm{~m}^{2}$ where other agents were also handled. The rest of the salbutamol base was sent to a separate finishing suite on the same site for conversion to the sulphate. Here, salbutamol base in batches of $35 \mathrm{~kg}$ was tipped into a reaction vessel and dissolved in dilute sulphuric acid. Crystalline salbutamol sulphate was precipitated by the addition of industrial methylated spirit. The salbutamol sulphate was filtered, the material hand scooped on to trays, and oven dried and tipped into a mechanical hopper for milling down to a size of 2 to $5 \mu \mathrm{m}$. The standard personal protection worn while handling the material was an airhood extending down to the waist and supplied by breathing air.

Limited exposure data were available. In 1979 , one personal sampler on an operator in the finishing suite was reported as showing an airborne concentration of $0.5 \mathrm{mg} \mathrm{m}^{-3}$, whereas three other environmental monitor- ing samplers showed values ranging from $0.05 \mathrm{mg} \mathrm{m}^{-3}$ in the background of the finishing suite to an indeterminate value that exceeded $0.2 \mathrm{mg} \mathrm{m}^{-3}$ inside the milling cubicle. Two further airborne background environmental samples in 1982 taken in the finishing suite at a time of day when no work was in progress showed values of $0.015 \mathrm{mg} \mathrm{m}^{-3}$ of airborne "active" salbutamol dust. In 1981, 18 swab test samples were taken over areas of about $40 \mathrm{~cm}^{2}$ in the finishing suite and showed values ranging from nil to in excess of 6 (median $0 \cdot 1$ ) $\mathrm{mg}$ salbutamol.

\section{Case descriptions}

CASE 1

At presentation in 1980 a 41 year old man had worked for the firm for six years as a process worker in the manufacture of a large number of drugs including salbutamol. $\mathrm{He}$ reported that on the days that salbutamol base was sulphated he and the other 10 workers experienced tremors. He gave a two year history of shortness of breath and wheeze that started about two hours after leaving work on the days he worked with salbutamol. $\mathrm{He}$ smoked less than 10 cigarettes a day. Skin prick tests to common antigens, salbutamol base $(10 \mathrm{mg} / \mathrm{ml})$, and salbutamol sulphate $(10$ $\mathrm{mg} / \mathrm{ml}$ ) were negative. Self recorded two hourly peak expiratory flow rate (PEF) recordings at work and at home ${ }^{3}$ for three weeks showed a small early rise in maximum PEF followed by a reduction during the one week he worked with salbutamol; there was not a full recovery during the next week. Figure 1 shows a comparison of the pooled

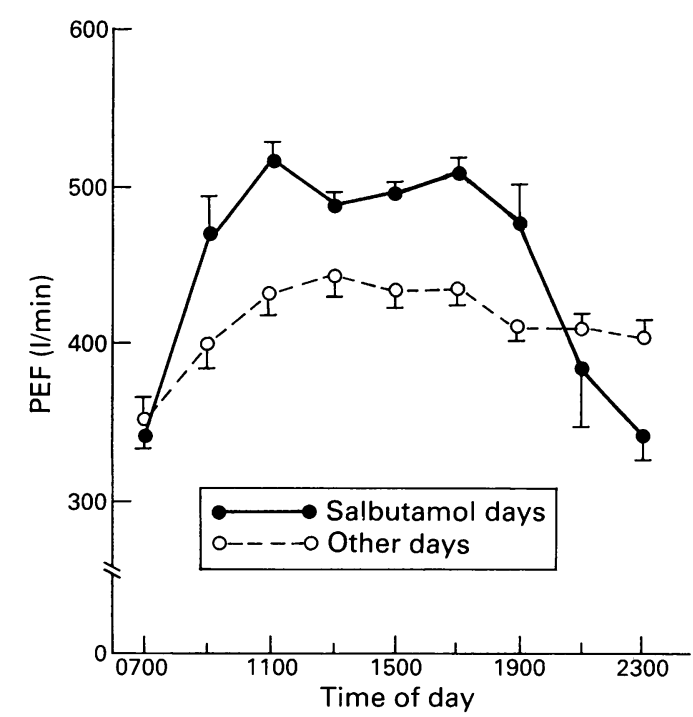

Figure 1 Pooled diurnal PEF patterns (mean (SEM)) for case 1 comparing salbutamol exposed days $(n=5)$ with other days $(n=15)$ as controls. 
diurnal pattern during work in the salbutamol finishing suite contrasted with control exposure. Days exposed to salbutamol had significantly higher (two sample $t$ tests) PEF readings at 0900 and 1100 (both $p<0.5$ ) and 1500 and 1700 (both $\mathrm{p}<0.01$ ) whereas they showed lower readings at $2300(p<0.01)$. Single blind bronchial inhalation testing ${ }^{4}$ with $100 \mathrm{mg}$ of powdered salbutamol base in $250 \mathrm{~g}$ dried lactose produced a $22 \%$ fall in forced expiratory volume in one second $\left(\mathrm{FEV}_{1}\right)$ after three hours (fig 2). There was no asthmatic reaction after a control challenge with $250 \mathrm{~g}$ of dried lactose powder or up to $1 \mathrm{~g}$ of milled salbutamol sulphate. Salbutamol (base, 400 $\mu \mathrm{g}$ ) given by metered dose inhaler produced an immediate $26 \%$ rise in $\mathrm{FEV}_{1}$ with no late fall. He was relocated to avoid contact with salbutamol and remained well for at least five years, left the firm, and was lost to follow up.

CASE 2

A 49 year old man worked for the same firm for six years packing several drugs including salbutamol base, usually for two to four weeks a year. He developed rhinitis after two years in this job, with improvement at weekends and on holiday. In November 1983 he developed a cough, chest tightness, and shortness of breath during the second day of packing a batch of salbutamol base. He was given a course of prednisolone and improved. Self recorded two hourly PEF readings for four weeks showed definite work related asthma (fig 3). He did not wish to undergo bronchial inhalation testing. The salbutamol packaging was moved to another site. He has remained asymptomatic in employment with the firm, and repeat PEF recordings were normal.

\section{Discussion}

The description of the handling of large quantities of fine dry material, as well as the air sampling and surface swab data, is consistent with a high personal exposure to airborne salbutamol. Despite the personal protection that was described as being worn, the reporting of tremors in the process workers, a well recognised pharmacological effect of uptake of high doses of salbutamol ${ }^{2}$ also suggests high exposure. This could have been the result of

Figure 2 Bronchial inhalation challenge test in case 1 with control powder, salbutamol base, and salbutamol sulphate. Treatment at stippled area.

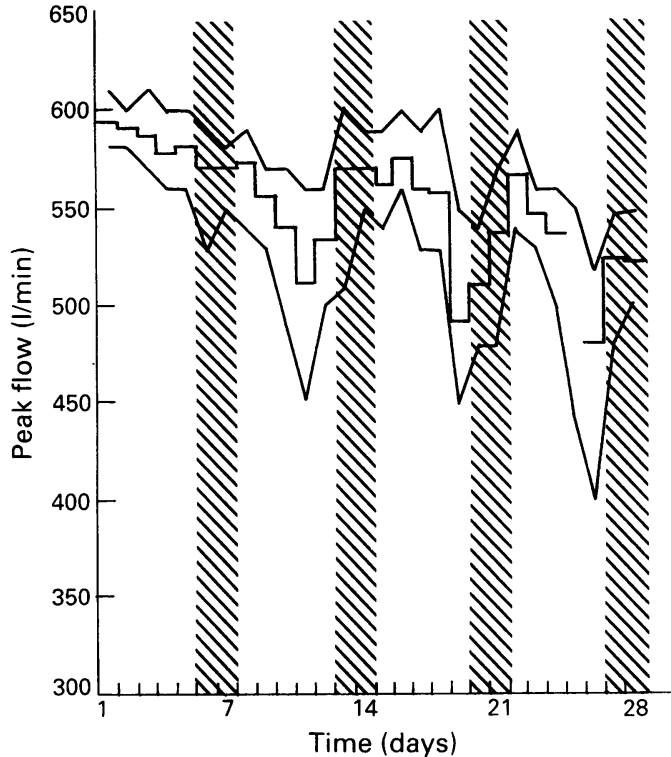

Figure 3 Serial $P E F$ recording in case 2 showing maximum, mean and minimum daily PEF (overall mean $549.6 \mathrm{l} / \mathrm{min}$ ) over a four week period including packing of salbutamol base. Weekends not at work are shown by diagonal hatching.

an inadequacy in the protective clothing, contamination during its removal, or compliance limited to the operations perceived to be at a higher risk.

Both workers had symptoms consistent with occupational asthma and one had symptoms of occupational rhinitis associated with exposure to salbutamol base. The pattern of PEF recordings in both workers, the late asthmatic reaction after bronchial inhalation testing with salbutamol base, the asymptomatic latent period of exposure, the absence of previous asthma, and recovery after avoidance of exposure, all suggest that salbutamol base was the primary cause of the asthma. The diurnal pattern of PEF showed a bronchodilator effect during the exposed working days consistent with the pharmacological effect of salbutamol. The subsequent drop in PEF might have been consistent with an allergic effect partly masked by a pharmacological effect.

The absence of a response to skin prick testing or to salbutamol base given by metered dose inhaler favours a pharmacological mechanism manifested at high doses, rather than an allergy, as the explanation for the workers' symptoms. Connolly et $a \bar{l}$ had found a reduction in airway sensitivity in both normal and asthmatic subjects after a four week course of inhaled salbutamol, whereas Holgate et al had shown a similar airway effect in normal subjects. In these and similar studies ${ }^{78}$ the biologically available dose was limited for ethical reasons and was likely to have been substantially smaller than in the two workers reported here. It is plausible that the exposures experienced here were sufficiently high to cause not only tolerance to the pharmacological effects of salbutamol but also a tachyphylactic effect to a degree manifest by airway hyperreactivity ${ }^{8}$ or rebound bronchoconstriction. Indeed there is evidence that sustained 
high exposures to salbutamol in normal ${ }^{9}$ as well as sensitised ${ }^{10}$ guinea pigs induce heightened airway reactivity to a range of spasmogens. It is most unlikely, however, that the high exposures reported here are relevant to the therapeutic use of salbutamol.

It is of interest that in case $1100 \mathrm{mg}$ of salbutamol (base) provoked a late asthmatic reaction whereas $1 \mathrm{~g}$ of salbutamol sulphate did not, as this suggests a qualitative difference between the two resulting from a property other than adrenoceptor occupancy. ${ }^{11}$

This report further highlights the caution that the therapeutic effects or the side effects of pharmaceuticals as given clinically are inadequate predictors of adverse occupational effects, especially on the organs of first contact. ${ }^{12}$ Control of exposure at source by enclosure and local exhaust ventilation is essential with additional personal protection as required. Regular personal monitoring of airborne pharmacologically active dust and appropriate health surveillance of pharmaceutical process workers should be pursued.

We thank Dr R Elton for his help with the statistical analysis.
1 Fawcett IW, Pepys J, Erooga MA. Asthma due to "glycyl compound" powder -an intermediate in production of compound" powder - an intermediate in

2 Reynolds JEF, ed. Martindale. The extra pharmacopoeia, 28th ed. London: the Pharmaceutical Press, 1982:29-31.

3 Burge PS, O'Brien IM, Harries MG. Peak flow rate records in the diagnosis of occupational asthma due to colophony. Thorax 1979;34:308-16.

4 Newman Taylor AJ, Davies R. Inhalation challenge testing. In: Weill $\mathbf{H}$, Turner-Warwick $M$, eds. Occupational lung disease: research approaches and methods. New York: Marcel Dekker, 1981:143-67.

5 Connolly ME, Tashkin DP, Hui KK, Littner MR, Wolfe RN. Selective Subsensitization of beta-adrenergic receptors in central airways of asthmatics and normal subjects during long-term therapy with inhaled salbutamol. $f$ Allergy Clin Immunol 1982;70:423-31.

6 Holgate ST, Stubbs WA, Wood PJ, McCaughey ES, Alberti KG, Tattersfield AE. Airway and metabolic resistance to intravenous salbutamol: a study in normal man. Clin Sci 1980;59:155-61.

7 Harvey JE, Tattersfield AE. Airway response to salbuta$\mathrm{mol}$. Effect of regular salbutamol inhalations in normal, atopic and asthmatic subjects. Thorax 1982;37:280-7.

8 Van Schayck CP, Graafsma SJ, Visch MB, Dompeling E Van Weel C, Van Herwaarden CLA. Increasing bronchial hyperresponsiveness after inhaling salbutamol dring during one year is not caused by subsensitization
salbutamol. F Allergy Clin Immunol 1990;86:793-800.

9 Galland BC, Blackman JG. Enhancement of airway reactivity to histamine by isoprenaline and related $\beta$-adrenoceptor agonists in the guinea-pig. Br $\mathcal{F}$ Pharmacol 1993; 108:1016-23

10 Hoshiko K, Morley J. Exacerbation of airway hyperreactivity by $( \pm)$ salbutamol in sensitised guinea pigs. Ipn f Pharmacol 1993;63:159-63.

11 Chapman ID, Buchheit KH, Manley P, Morley J. Active enantiomers may cause adverse effects in asthma. Trends Pharmacol Sci 1992;13:231-2.

12 Agius RM. Occupational exposure limits for therapeutic substances. Ann Occup Hyg 1989;4:555-62. 